\section{Commentary: The optimal lymphadenectomy: The never-ending story}

\author{
Siva Raja, MD, PhD, FACS
}

The value of lymphadenectomy during esophagectomy has been a highly debated subject in the surgical treatment of esophageal cancer. While most agree that it has a prognostic value, there has been less consensus on its therapeutic value. In the editorial by Dr Altorki ${ }^{1}$ in this month's Journal, we benefit from the expert opinion of a master esophageal surgeon on 2-field versus 3-field lymphadenectomy. His commentary is based on a recently published comparative study that examines this question in the setting of esophageal squamous cell cancer. ${ }^{2}$ This large study failed to show a difference in survival based on extent of lymphadenectomy that was perhaps previously seen in a larger Japanese trial. ${ }^{3}$ Dr Altorki provides an in-depth analysis of the study and its limitations. He also provides his perspective on this topic as well as on the matter of lymphadenectomy. There can be no disagreement on his conclusion that "adequate lymphadenectomy... is good for patients."

In my mind, this discussion of 2-field lymphadenectomy versus 3-field lymphadenectomy is of primary concern in proximal (and perhaps some mid) esophageal cancers, which tend to be esophageal squamous cell cancer. Most in the Western world would consider a cervical node metastasis as an out-of-field metastasis when dealing with distal esophageal cancer. As such, surgery is not offered for these patients by virtue of having no proven survival benefit from the addition of an esophagectomy over medical therapy. This point is highlighted by the poor 5-year survival of patients after esophagectomy with lower-third adenocarcinoma and cervical nodal

\footnotetext{
From the Department of Thoracic and Cardiovascular Surgery, Heart and Vascular Institute, Cleveland Clinic, Cleveland, Ohio.

Disclosures: The author reported no conflicts of interest.

The Journal policy requires editors and reviewers to disclose conflicts of interest and to decline handling or reviewing manuscripts for which they may have a conflict of interest. The editors and reviewers of this article have no conflicts of interest.

Received for publication July 20, 2021; revisions received July 20, 2021; accepted for publication July 21, 2021; available ahead of print July 28, 2021.

Address for reprints: Siva Raja, MD, PhD, FACS, Department of Thoracic and Cardiovascular Surgery, Heart and Vascular Institute, Cleveland Clinic Foundation, J41, 9500 Euclid Ave, Cleveland, OH 44195 (E-mail: rajas@ccf.org).

J Thorac Cardiovasc Surg 2022;163:1700-1 $0022-5223 / \$ 36.00$

Copyright $₫ 2021$ Published by Elsevier Inc. on behalf of The American Association for Thoracic Surgery

https://doi.org/10.1016/j.jtcvs.2021.07.035
}
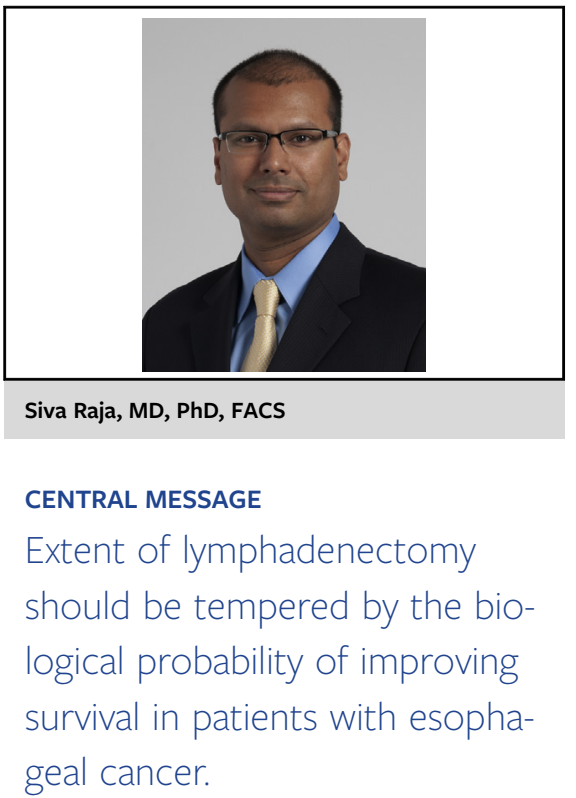

metastasis in the Cornell and the Leuven study showing $15 \%$ and $12 \%$, respectively. ${ }^{4,5}$

Second, the number of patients with isolated cervical nodal metastasis (occult or otherwise) is likely very small in mid- and distal cancers. In the more-common scenario, where there is clinical node-positive disease, most would get neoadjuvant therapy. When there is nodal metastasis noted in the resection specimen in clinically nodenegative patients, they received adjuvant therapy. Therefore, it would indeed be difficult to identify any benefit in survival from the cervical lymphadenectomy above and beyond that provided by a 2-field lymphadenectomy and chemoradiotherapy. In the absence of a clear survival benefit, one would also be hard pressed to subject the patient to increased risk of recurrent nerve paralysis from the additional dissection.

The data collected for the purpose of creating the 8th edition of the AJCC staging manual have also been used to address this question of the value of lymphadenectomy. The paper by Rizk and colleagues ${ }^{6}$ identified resecting at least 10,20, and >30 lymph nodes to maximize survival in patients with esophageal cancer undergoing esophagectomy (without neoadjuvant therapy) for pT1, T2, and T3/ 4 , respectively. Similarly, our group has shown there was an improvement in survival up to 25 to 30 lymph nodes in patients with esophageal adenocarcinoma undergoing esophagectomy after neoadjuvant therapy. ${ }^{7}$ Based on these papers, I tend to agree with Dr Altorki that the bar of 15 lymph nodes in an esophagectomy is in indeed a low bar! 
The adequate lymphadenectomy can be defined by number of lymph nodes or perhaps by location (should the TIGER trial show improved prognostication of the stations of nodes examined over just number of lymph nodes resected). ${ }^{8}$ However we define it, there is likely value in local regional lymphadenectomy for local control and overall survival in appropriately selected patients. The presence of cervical node involvement in a distal tumor is a negative prognostic indicator, especially in esophageal adenocarcinoma and usually considered unresectable based on extent of disease. This question we are discussing today is best put in perspective by this popular quote from Dr Blake Cady, who stated "Biology is King, selection of cases is Queen, and the technical details of surgical procedures are princes and princesses of the realm who frequently try to overthrow the powerful forces of the King and Queen, usually to no long-term avail, although with some temporary apparent victories." In the Fudan trial, this philosophy is highlighted by the cervical nodal recurrence rates where this rate was very similar in the 2 -field $(7 \%)$ and 3 -field $(6 \%)$ dissection groups. ${ }^{2}$ If there was value to the additional lymphadenectomy, one should have at least seen better regional control. In determining the extent of lymphadenectomy, we need to first see if it is biologically reasonable for the individual patient. With immuno-oncology entering the arena, the end to this story may be further away than we thought.

\section{References}

1. Altorki N. Two-field lymph node dissection or three-field lymph node dissection. What's in a name? J Thorac Cardiovasc Surg. 2022;163:1695-7.

2. Li B, Zhang Y, Miao L, Ma L, Luo X, Zhang Y, et al. Esophagectomy with threefield versus two-field lymphadenectomy for middle and lower thoracic esophageal cancer: long-term outcomes of a randomized clinical trial. J Thorac Oncol. 2021; 16:310-7.

3. Isono K, Sato H, Nakayama K. Results of a nationwide study on three-field lymph node 118 dissection of esophageal cancer. Oncology. 1991;48:411-20.

4. Altorki N, Kent M, Ferrara C, Port J. Three-field lymph node dissection for squamous cell and adenocarcinoma of the esophagus. Ann Surg. 2002;236: 177-83.

5. Lerut T, Nafteux P, Moons J, Coosemans W, Decker G, De Leyn P, et al. Threefield lymphadenectomy for carcinoma of the esophagus and gastroesophageal junction in 174 R0 resections: impact on staging, disease free survival, and outcome: a plea for adaptation of TNM classification in upper-half esophageal carcinoma. Ann Surg. 2004;240:962-72.

6. Rizk NP, Ishwaran H, Rice TW, Chen LQ, Schipper PH, Kesler KA, et al. Optimum lymphadenectomy for esophageal cancer. Ann Surg. 2010;251:46-50.

7. Raja S, Rice TW, Murthy SC, Ahmad U, Semple ME, Blackstone EH, et al; Worldwide Esophageal Cancer Collaboration Investigators. Value of lymphadenectomy in patients receiving neoadjuvant therapy for esophageal adenocarcinoma. Ann Surg. December 16, 2019 [Epub ahead of print].

8. Hagens ERC, van Berge Henegouwen MI, van Sandick JW, Cuesta MA, van de Peet DL, Heisterkamp J, et al. Distribution of lymph node metastases in esophageal carcinoma [TIGER study]: study protocol of a multinational observational study. BMC Cancer. 2019;19:662.

9. Cady B. Basic principles in surgical oncology. Arch Surg. 1997;132:338-46. 